\title{
Melanin-Based Coloration in Juvenile Kestrels (Falco tinnunculus) Covaries with Anti-Predatory Personality Traits
}

\author{
Valentijn van den Brink*, Isabelle Henry*, Kazumasa Wakamatsu† \& Alexandre Roulin* \\ * Department of Ecology and Evolution, University of Lausanne Lausanne, Switzerland \\ $\uparrow$ Department of Chemistry, Fujita Health University School of Health Sciences, Toyoake, Aichi, Japan
}

\section{Correspondence}

Valentijn van den Brink, Department of Ecology and Evolution, University of Lausanne, CH-1015 Lausanne, Switzerland. E-mail:valentijn.vandenbrink@unil.ch

Received: February 18, 2012

Initial acceptance: April 11, 2012

Final acceptance: April 27, 2012

(L. Fusani)

doi: 10.1111/j.1439-0310.2012.02057.x

\begin{abstract}
Recent studies have shown that melanin-based coloration is associated with the ability to cope with stressful environments, potentially explaining why coloration covaries with anti-predator behaviours, boldness and docility. To investigate whether these relationships are consistent across species, we performed a study in the European kestrel (Falco tinnunculus). Similar to our results found previously in the barn owl (Tyto alba), nestling kestrels displaying a larger sub-terminal black tail band stayed on their back longer (tonic immobility test) and breathed at a lower rate than individuals with a smaller black band when handled. However, in contrast to barn owls, nestling kestrels with a larger black tail band were more aggressive and more agitated. Our results strengthen the hypothesis that melanin coloration is related to stress response and in turn to the reaction to predators, a very important personality trait (i.e. boldness).
\end{abstract}

\section{Introduction}

Data are accumulating on the possibility that melanin-based coloration is associated with behavioural syndromes. Darker melanic individuals are usually more aggressive and sexually active (Ducrest et al. 2008), and a recent study in tortoises has shown that dark coloration is associated with anti-predator behaviour (Mafli et al. 2011). The possibility that melanin-based coloration could be related to all five categories of behavioural syndromes (aggressiveness, boldness, activity, exploration and sociality; Reale et al. 2007) therefore starts to attract researchers (e.g. Mateos-Gonzàlez \& Senar 2012). Given that in many species inter-individual variation in melanin-based coloration is under strong genetic control, covariation between melanin colour and personality traits could arise if genes encoding for colour pleiotropically regulate behaviour (Ducrest et al. 2008). From a physiological point of view, glucocorticoids may explain why behaviour is associated with melanin coloration. In several species, glucocorticoid-dependent stress responses are differentially expressed in dark- and pale-coloured individuals, as shown in Harris's spar- row (Zonotrichia querula, Rohwer \& Wingfield 1981), the barn owl (Tyto alba, Almasi et al. 2010), fish (Kittilsen et al. 2009), deer mice (Peromyscus maniculatus, Hayssen et al. 2002) and dogs (Bennett \& Hayssen 2010).

On the basis of the finding that eumelanism is associated with stress response, Van den Brink et al. (2012) proposed the hypothesis that dark and light individuals may differ in their response to predation risk. Accordingly, these authors showed that when exposed to the threat of a potential predator, barn owl nestlings with larger eumelanic spots hissed more, were more docile, needed fewer attempts to induce death feigning [tonic immobility (TI) test] and breathed at a lower rate than those with smaller spots. Given that glucocorticoid stress responses appear to be colour dependent in organisms that are phylogenetically as distinct as fish, mammals and birds, the results found in the barn owl with respect to predation response might also apply to other animals. In a first attempt to answer this question, we performed a study in the Eurasian kestrel (Falco tinnunculus). The kestrel was chosen because it can use nest boxes not occupied by barn owls (and hence can 
be considered a sort 'by-catch' of our long-term barn owl research in the same area). The kestrel is a suitable species to study the relationships between behavioural traits and colour, because individuals from the same population also vary in melanic coloration. It differs from the barn owl in that it is diurnal, so although a closely related species, we feel it could provide a first indication if the previously found results can be generalised to other species. Another important difference is that in the kestrel, males are darker eumelanic than females, whereas in the barn owl, this is the opposite, with females being darker eumelanic than males.

Kestrels are small diurnal raptors, common in most of Europe, which display colour traits that vary between individuals in the form of a large sub-terminal black-eumelanic tail band and pheomelanic reddish brown coloration of the back and tail feathers. We conducted similar experiments as those performed in the study on nestling barn owls (Van den Brink et al. 2012) aimed at measuring the direct stress involved in the encounters with potential predators. We began by measuring eumelanin and pheomelanin content of feathers to confirm the type of melanin in the traits studied. Then, we measured how docile nestling kestrels were when handled. Corresponding tests involved holding an individual by the legs and scoring whether it then threatens or grabs the observer with its claws and presenting a stick to the nestling to measure the strength with which it grabs the stick. Then, we performed the TI test to assess how long individuals remain immobile in front of a predator (Gallup 1974). Finally, we counted the number of times an individual breathes per unit time when handled. This provided us with a measure of the level of stress, because also in great tits (Parus major) breathing rate is correlated with corticosterone levels in the blood (Carere $\&$ Oers 2004) and exploratory behaviour later in life (Fucikova et al. 2009).

On the basis of the results obtained in the barn owl (Van den Brink et al. 2012), we predict individuals that display a larger sub-terminal black tail band to be more resistant to stress by being more docile when handled, to stay longer on their back when placed there and to show a lower breathing rate. We also studied pheomelanic coloration, because a recent study by Roulin et al. (2011) showed that physiological traits can be inversely related to eu- and pheomelanin coloration. These results suggest that a relationship between phenotypic traits and pheomelanin could perhaps be of opposite sign than the relationship of these phenotypic traits with eumelanin.

\section{Methods}

\section{Study Species and Study Area}

The kestrel is one of the most common small diurnal raptors of Europe (Glutz von Blotzheim 1987). It lives in open habitat where it feeds mainly on various vole species. Adults are sexually dimorphic, with females about $20 \%$ larger and heavier than males. Females are reddish brown with black bars on the back and tail. In contrast, adult males show blue-grey feathers on the head, rump, upper tail coverts and tail. They are reddish with black spots on the back (Village 1990). Individuals of both sexes display a large, subterminal black tail band.

We studied a kestrel population breeding in nest boxes in western Switzerland $\left(46^{\prime \prime} 49^{\prime} \mathrm{N}, 6^{\prime \prime} 50^{\prime} \mathrm{E}, 500\right.$ $600 \mathrm{~m}$ altitude). These boxes are placed on the side of farms and are intended for barn owls (Tyto alba), but when unoccupied by barn owls, they can be used by kestrels. We studied the kestrels in 2009 and 2010, which were exceptionally poor years for barn owls, leaving many boxes available for kestrels to breed. Between June and August, we visited 30 nests with a total of 62 nestlings ( 30 females and 32 males) in 2009 and 25 nests with 86 nestlings (of unknown sex) in 2010. In 2009, we visited each box two times for our experiments, once when the nestlings were (mean \pm SE) $15 \pm 0.2 \mathrm{~d}$ old and once at $22 \pm 0.2 \mathrm{~d}$. In a separate visit, just before fledging at $26.7 \pm 0.2 \mathrm{~d}$, we only measured colour traits. In 2010, we wanted to focus on certain aspects of our 2009 study, and therefore, we only visited each nest once, to minimise unnecessary disturbance. As a result, we could therefore only determine approximate age of the nestlings, because we did not visit the nests on the day of hatching. We based our estimates on predicted hatching dates and comparison of wing length and body mass to measurements of nestlings of known age from previous years. We only performed the assessment of behaviour on one visit, shortly before fledging, when nestlings were between approx. 25 and $30 \mathrm{~d}$ old.

\section{Body Measurements and Assessment of Plumage Traits}

At each visit to the nest, we recorded the body mass of the nestlings to the nearest $0.1 \mathrm{~g}$ and measured the length of their left wing and tail to the nearest $\mathrm{mm}$ and tarsus length to the nearest $0.1 \mathrm{~mm}$. We also measured to the nearest $0.1 \mathrm{~mm}$ the width of the subterminal black band on all twelve tail feathers during the last (and in 2010 during the only) visit, shortly before fledging. Subsequently, for each individual, we 
calculated the mean width of all sub-terminal black bands to be used in statistical analyses. The width of this band does not covary with the age at which we measured it (Pearson's correlation: $r=0.03, \mathrm{n}=81$, $\mathrm{p}=0.8$ ), but the length of the tail does covary with age $(r=0.401, \mathrm{n}=82, \mathrm{p}=0.0002)$ and the width of the tail band also correlates with the length of the tail $(r=0.28, \mathrm{n}=81, \mathrm{p}=0.01)$. The increased width of the tail band with longer tail length might be related to a possible signalling function, but as we are interested in the amount of eumelanin produced and deposited, we will focus on the absolute width here. To remove variation attributable to tail length, we used the residual of tail length with age at measuring as covariate.

We also collected three feathers from the back and the tail for reflectance spectra measurements. We measured the reflectance spectra in the 300-700 nm range using an Ocean Optics S2000 spectrophotometer (Ocean Optics, Dunedin, FL, USA) with a deuterium-halogen 2000 light source (Mikropack, Ostfildern, Germany). The reflectance is expressed as the proportion of light reflected in comparison with a spectralon white standard disc (WS type). For each reflectance spectrum, we calculated the brown chroma as $\left(\mathrm{R}_{700 \mathrm{~nm}}-\mathrm{R}_{600 \mathrm{~nm}}\right) / \mathrm{R}_{\text {mean }}$, where $\mathrm{R}_{\text {mean }}$ is the mean reflectance in the visible light (300$700 \mathrm{~nm}$ ). The brown chroma represents the contribution of the red part of the spectrum relative to the complete visible part of the spectrum, and we used this as a proxy for pheomelanin coloration.

\section{Determination of Melanin Content from Feathers}

In 2006, we plucked wing coverts, upper-tail coverts and tail feathers from three adult kestrels (one male and two females) found dead along roads and stored in the laboratory at $-20^{\circ} \mathrm{C}$. Our aim was to identify and measure the concentration of melanin pigments in the reddish, black and greyish parts of feathers. We thus pooled feathers from the different body parts presenting the same colour patterns.

K. Wakamatsu identified the concentration in pheomelanin and eumelanin in kestrel feathers (Wakamatsu et al. 2002; Ito et al. 2011). Microanalytical methods were developed to quantify the amounts of eumelanin and pheomelanin. Those assays were based on the formation of specific degradation products such as pyrrole-2,3,5-tricarboxylic acid (PTCA) by alkaline $\mathrm{H}_{2} \mathrm{O}_{2}$ oxidation of eumelanin and 4-amino-3-hydroxyphenylalanine (4-AHP) by reductive hydrolysis of pheomelanin with hydriodic acid (HI). Alkaline $\mathrm{H}_{2} \mathrm{O}_{2}$ oxidation of feathers was performed as follows: $1.0-1.5 \mathrm{mg}$ of feather was taken in 10-ml screw-capped test tubes, to which $375 \mu \mathrm{l}$ of $1 \mathrm{M} \mathrm{K} \mathrm{K}_{2} \mathrm{CO}_{3}$ and $20 \mu \mathrm{l}$ of $30 \% \mathrm{H}_{2} \mathrm{O}_{2}$ were added. The mixtures were mixed in $25 \pm 1{ }^{\circ} \mathrm{C}$ for $20 \mathrm{~h}$. The residual $\mathrm{H}_{2} \mathrm{O}_{2}$ was decomposed by the addition of $50 \mu \mathrm{l}$ of $10 \% \mathrm{Na}_{2} \mathrm{SO}_{3}$, and the mixtures were then acidified $(\mathrm{pH} 4.0)$ with $135 \mu \mathrm{l}$ of $6 \mathrm{~m} \mathrm{HCl}$. After vortex-mixing, the reaction mixtures were centrifuged at $4000 \mathrm{~g}$ for $1 \mathrm{~min}$, and aliquots $(80 \mu \mathrm{l})$ of the supernatant fluids were directly injected into the HPLC system. HI hydrolysis was performed by heating $1.0-1.5 \mathrm{mg}$ of feather, $30 \mu \mathrm{l}$ of $30 \% \mathrm{H}_{3} \mathrm{PO}_{2}$ and $500 \mu \mathrm{l}$ of $57 \% \mathrm{HI}$ in a screw-capped tube at $130^{\circ} \mathrm{C}$ for $20 \mathrm{~h}$, after which the mixture was cooled. An aliquot $(100 \mu \mathrm{l})$ of each hydrolysate was transferred to a test tube and evaporated to dryness using a vacuum pump connected to a dry ice-cooled vacuum trap and two filter flasks containing $\mathrm{NaOH}$ pellets. The residue was dissolved in $200 \mu \mathrm{l}$ of $0.1 \mathrm{~m} \mathrm{HCl}$. An aliquot $(10 \mu \mathrm{l})$ of each solution was analysed on the HPLC system. $\mathrm{H}_{2} \mathrm{O}_{2}$ oxidation products were analysed with the HPLC system consisting of a JASCO 880-PU liquid chromatograph (JASCO Co., Tokyo, Japan), a Shiseido $C_{18}$ column (Shiseido Capcell Pak MG; $4.6 \times 250 \mathrm{~mm} ; 5-\mu \mathrm{m}$ particle size) and a JASCO UV detector. The mobile phase was $0.1 \mathrm{~m}$ potassium phosphate buffer $(\mathrm{pH} 2.1)$ : $\mathrm{MeOH}, 99: 1(\mathrm{v} / \mathrm{v})$. Analyses were performed at $35^{\circ} \mathrm{C}$ at a flow rate of $0.7 \mathrm{ml} / \mathrm{min}$. Absorbance of the eluent was monitored at $269 \mathrm{~nm}$. HI reductive hydrolysis products were analysed with an HPLC system consisting of a JASCO 880-PU liquid chromatograph, a JAS$\mathrm{CO} \mathrm{C}_{18}$ column (JASCO Catecholpak; $4.6 \times 150 \mathrm{~mm}$; $7 \mu \mathrm{m}$ particle size) and an EICOM ECD-300 electrochemical detector. The mobile phase used for the analysis of AHP was $0.1 \mathrm{~m}$ sodium octanesulfonate and 0.1 $\mathrm{M} \mathrm{Na}_{2}$ EDTA:MeOH, 98:2 (v/v). Analyses were performed at $35^{\circ} \mathrm{C}$ at a flow rate of $0.7 \mathrm{~m}$. The electrochemical detector was set at $+500 \mathrm{mV}$ vs. an $\mathrm{Ag} / \mathrm{AgCl}$ reference electrode.

\section{Tonic Immobility Test}

Using the method described by Jones \& Faure (1981), Jones (1986) and Van den Brink et al. (2012), a single person $(\mathrm{VvdB})$ put each nestling on its back and restrained it for $10 \mathrm{~s}$ with a hand on its breast in a large wooden box $(40 \times 40 \mathrm{~cm})$ fitted with a wire mesh cover to prevent escape. The hand was then removed and the time until the nestling moved to turn itself and stand on its feet again was measured. The same person stayed nearby within sight of the nestling until the end of the test. Some individuals are more readily induced into the state of TI than others, and it is recommended to repeat the test several times in a 
row if an individual does not stay in the first attempt. Therefore, we tested those individuals that stayed $<15$ s again for a maximum of three times (Jones $\&$ Faure 1981; Jones 1986; Van den Brink et al. 2012). Thus, each individual was tested between one and three times (mean number of attempts, $1.9 \pm 0.1 \mathrm{SE}$ ), which gave us a first measure of the motivation to stay on its back. Over the one to three trials, we considered the longest duration this individual stayed on its back as a second measure of TI (mean duration, 53.9 $\mathrm{s} \pm 5.1$ $\mathrm{SE}$ ). If an individual stayed longer than $120 \mathrm{~s}$, we stopped the test, and hence, $120 \mathrm{~s}$ was the maximum duration recorded. Individuals that never stayed on their back were scored a zero value for the TI duration. As an extra measure of personality, we also measured 'righting time' - the time it took for an individual to right itself again when placed on either side of its body, without restraint (mean duration, $3.2 \mathrm{~s} \pm 0.8$ ). The main difference with the TI test is that this procedure does not involve restraint and only places the individual on its left or right side (mean values for three repeats on both sides were recorded), which might provoke a different reaction than the TI test.

\section{Breathing Rate}

The number of times an individual breathes in one minute, as measured by counting the number of breast movements, is an indication of response to handling stress (Carere \& Oers 2004; Fucikova et al. 2009). In 2010, we assessed breathing rate in nestlings by counting breast movements in a one-minute period immediately after being taken out of their nest box. Because we recorded breathing rate in more than one nestling per visit, and stress levels may rise after removal from the nest box (Carere $\&$ Oers 2004), for each individual we recorded the time elapsed between when we opened the nest box for the first time and when we started to count breast movements (mean number of breathing movements, $127 \pm 2.8 \mathrm{SE}$ ); thus, we considered it a stable measure of response to handling stress.

\section{Docility}

We assessed aggression towards the handler and the degree of agitation during the two visits for all nestlings on a $0-3$ scale. Score 0 was assigned to nestlings that did not express any aggressive behaviour, score 1 to those that tried to bite us once or a few times, score 2 for those that frequently scratched, attacked or tried to pinch with their beak, and score 3 was assigned to individuals that were extremely aggressive by grab- bing with their bill and claws and when trying to catch the bird to be handled were on their back with claws raised (mean score, $0.9 \pm 0.1 \mathrm{SE}$ ). Assessments of agitation were given according to a similar index (0-3): the minimal score (0) being assigned to nestlings that did not move or call during manipulation, whereas the maximal score (3) corresponds to nestlings which were struggling, flapping their wings and/or hissing all the time (mean score, $1.7 \pm 0.1 \mathrm{SE}$ ).

\section{Stick Grabbing}

Nestling kestrels can adopt a defensive posture where they position themselves on their back and strongly thrust their claws at the predator. To record this aggressive behaviour, we presented individuals with a round $(2 \mathrm{~cm}$ diameter) wooden stick and recorded the intensity with which the stick was grabbed. Score 0 was assigned to individuals that did not grab the stick at all, score 1 to individuals that moved their talons towards grabbing, but did not grab the stick, score 2 to individuals that grabbed the stick, but weakly (i.e. the stick could be easily removed from the grip of the individual again by simply pulling the stick away). Finally, score 3 indicated that individuals had a very strong grip, where the individual held on powerfully to the stick and its talons had to be removed one by one from the stick (mean score: $1.3 \pm 0.05 \mathrm{SE}$ ).

\section{Lifting by Claws}

We also measured the tendency to grab and hold onto our hand when we slightly lifted the birds up while holding them by their tarsi. We measured this on a scale of $0-3$ as follows: Zero meant the bird did not grab at all, one was weak grabbing, two is strong grabbing, and three was recorded as very strong grabbing with flapping of wings in an attempt to sit upright (mean score, $1.2 \pm 0.06 \mathrm{SE}$ ).

\section{Statistical Procedures}

All statistical tests were performed with the software program JMP 9.01 (SAS Institute, Cary, NC, USA), tests were two-tailed, $\mathrm{p}$ values smaller than 0.05 were considered significant, and model fits were compared using $\triangle$ AIC. All results are presented as means with standard errors.

\section{Main Experiment in 2009}

We analysed the data for 2009 and 2010 separately, because in 2010 , only one visit per nest was made. To 
reduce the amount of variables we tested and to avoid using multiple correlated variables in our models (Quinn \& Keough 2002), we performed a principal components analysis (PCA) on the mean individual values for 2009 and another PCA for the mean nest values in 2010. For the data of 2009, the initial PCA contained TI duration, number of TI attempts, righting time, aggression, agitation, stick grabbing and lifting from claws. We retained the first two components of this PCA, because they had eigenvalues $>1$ (2.3 and 1.6) (Quinn \& Keough 2002). After inspection of the loading matrix for the different variables of the PCA (Fig. la), we found that the variable 'righting time' did not contribute strongly to the overall fit of the PCA as defined by a loading lower than 0.4 on both components (loading on PCl and PC2 of 0.38 and -0.20 , respectively). The variance explained by the first two components also increased from $32.6 \%$ to $36.8 \%$ for PCl and from $22.4 \%$ to $25.8 \%$ for PC2 after removal of this variable. The eigenvalues of
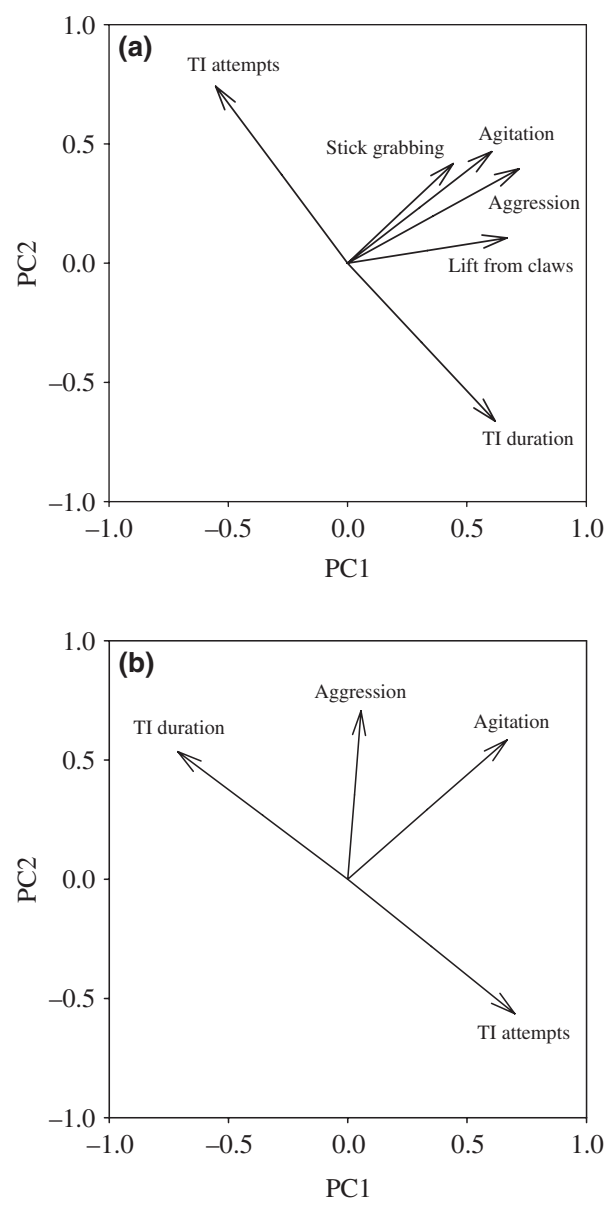

Fig. 1: Loading plots for (a) 2009 and (b) 2010 of principal components analysis on behavioural traits in nestling kestrels. Displayed are the loadings of the variables used on PC1 and PC2. these two new PCs were 2.21 and 1.54, respectively. They were used in subsequent analyses with eumelanin- (width of the black tail band) and pheomelaninbased (brown chroma value) traits. We calculated repeatabilities and standard errors following Becker (1984) and Lessels \& Boag (1987) for PCl and PC2, but found only $\mathrm{PC} 2$ repeatable between visits (PC1: $F_{1,89}=0.64, \mathrm{p}=0.98 ;$ PC2: $F_{1,89}=1.97, \mathrm{p}=0.002$, $r=0.35 \pm 0.09$ ). We constructed a repeated measures mixed model with individual identity nested in the nest of rearing and individual as random variables to account for repeated measures and similar genetic background of siblings. The dependent variable in two separate models was PC1 or PC2. Predictor variables were sex, age rank in the nest of rearing (because the dynamics of sibling interactions in the nest could perhaps influence behaviour owing to age differences between siblings), age at the experiment (to account for possible influences of developmental stage), residual tail length (tail length corrected for age) and width of black tail band. In an identical set of models, we used pheomelanic coloration instead of the width of the black tail band.

\section{Minor Experiment in 2010}

To confirm part of the results obtained in 2009, we performed a small study in 2010. We did not find an effect of sex on personality traits in 2009, and because the width of the black tail band was not sexually dimorphic (see Results), we did not identify nestling sex in 2010. We also did not know the exact age, and to reduce variation that might have been caused by this, we decided to use mean values per nest for the analyses. Furthermore, given the absence of any relationship between personality and pheomelanin-based coloration in 2009, we did not measure this colour trait in 2010. After analysing the 2009 data, we removed several behavioural tests that were least informative from our protocol for 2010. Righting time, stick grabbing and lifting from claws were all redundant with TI or docility measurements. When we re-analysed the 2009 data with only the remaining variables and with mean values per nest over all visits, as in 2010, we find qualitatively similar significant results as for the complete analysis with all variables. We measured three personality traits (TI, aggression and agitation) and breathing rate in 2010, and we calculated mean values per nest. We performed a PCA on these traits and found that the first two PCs explained $34.3 \%$ and $29.9 \%$ of variation (Fig. lb). The loading matrix showed that the breathing rate (loadings of 0.02 and 0.13 ) did not contribute to the 
first two PCs (eigenvalues of 1.74 and 1.45), but it was the only variable that contributed strongly to the variation (loading of 0.97) in the third PC (eigenvalue of 1), and therefore, breathing rate was removed from the PCA and analysed separately. This improved the overall fit of the PCA to $42.5 \%$ for PCl and to $36.9 \%$ for PC2, with eigenvalues of 1.74 and 1.44, respectively. We used the resulting two PCs in subsequent analyses with the width of the black tail band as predictor. For the analysis of breathing rate, we introduced as a covariate the mean time span between the moment when we opened the nest box and recorded breathing rate.

\section{Results}

\section{Melanin Content}

Eumelanin pigments were more abundant than pheomelanin pigments in black (mean \pm SE, $41809 \pm$ $10592 \mathrm{ng} / \mathrm{mg}$ vs. $536 \pm 271)$ and grey feathers $(62696 \pm 15664$ vs. $763 \pm 303)$, while the opposite was found for reddish feathers (3367 \pm 589 vs. $7923 \pm 1761)$. Thus, the ratio eumelanin/pheomelanin was 374 for black feathers, 217 for grey feathers and 0.5 for reddish feathers. These measurements confirm the eumelanin and pheomelanin composition of the studied colour traits.

\section{Main Experiment in 2009}

The final model showed that the wider the black tail band $\left(F_{1,78.07}=5.3, \mathrm{p}=0.02\right.$, Fig. 2$)$ and the older the nestlings when tested $\left(F_{1,88.6}=109.8, \mathrm{p}<0.0001\right)$,

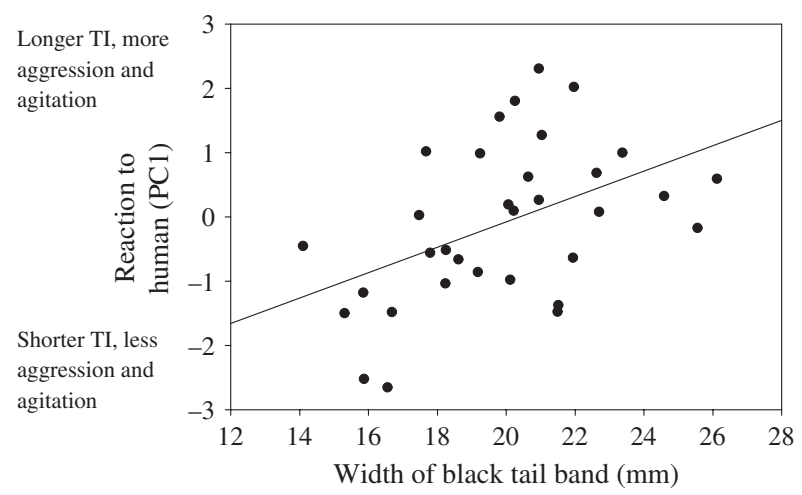

Fig. 2: Relationship between PC1 of a PCA on the reaction to human intrusion of the nest box and the width of the sub-terminal black tail band in nestling kestrels in 2009. A higher value in PC1 reflects longer tonic immobility (TI) duration, more aggression and agitation, stronger grabbing reflex and strength of grabbing, along with fewer attempts necessary to induce TI. the higher the value for PCl was. Nestling sex had no significant effect on $\operatorname{PCl}\left(F_{1,50.3}=0.16, \mathrm{p}=0.69\right)$, nor did age rank $\left(F_{1,72.11}=0.05, \mathrm{p}=0.83\right)$ and residual tail length $\left(F_{1,89.5}=2.4, \mathrm{p}=0.13\right)$. Model selection by comparing $\triangle \mathrm{AIC}$ between full and reduced models showed that the final model with only width of tail band and age during experiment produced the best fit ( $\triangle \mathrm{AIC}$ between final and next closest model was eight points). The PCA showed a clear clustering of the aggression, agitation, lifting from claws and stick grabbing (Fig. la). This was also supported by similar loadings of these variables onto the PCs. On the basis of the loading values, this means that individuals with larger tail bands were more aggressive, more agitated, grabbed the stick more strongly, reacted stronger to lifting from the claws and stayed in TI longer than individuals with smaller tail bands. TI was also achieved in fewer attempts in individuals with a wider black tail band. The models for PC2 and the model for PCl with the chroma values were all non-significant (all p-values $>0.21$ ). Correlations between the different behavioural traits are shown in Table 1.

The different number of tests per individual for the TI experiment could have biased our results, and therefore, we repeated our analyses with only the result of the first attempt to induce TI. The results remain significant (age, $F_{1,46.69}=31.8, \mathrm{p}<0.0001$; terminal black tail band, $F_{1,48.2}=7.7, \mathrm{p}=0.008$ ), and therefore, we are confident that our method of testing has not influenced the outcome of our analyses.

\section{Minor Experiment in 2010}

Both PC1 and PC2 did not show a significant relationship with the width of the black tail band (all p-values $>0.54$ ). The placement in opposite corners on the loading plot (Fig. lb) of the TI duration and the number of attempts to induce TI is confirmed by their strong negative correlation (Pearson's correlation: $r=-0.79, \mathrm{p}<0.0001)$, whereas aggression and agitation are positively correlated $(r=0.64, \mathrm{p}=0.0007$, Table 1). The larger the black tail band, the fewer breathing movements per minute were made (multiple regression analysis: $F_{1,23}=7.137, \mathrm{p}=0.014$; Fig. 3). The time after opening of the nest box had no effect on the number of breathing movements $\left(F_{1,22}=1.639, \mathrm{p}=0.21\right)$; hence, we removed this variable from the final model.

\section{Discussion}

We found that in 2009, the wider the black tail band in nestling kestrels was, the more they were aggressive, 
Table 1: Pairwise correlations for variables used in principal components analysis of behavioural traits for data from 2009 (a) and 2010 (b) in nestling kestrels

\begin{tabular}{|c|c|c|c|c|c|c|}
\hline & TI attempts & TI duration & Recovery & Stick grab & Lift from claws & Aggression \\
\hline \multicolumn{7}{|l|}{ (a) } \\
\hline TI attempts & - & - & - & - & - & - \\
\hline TI duration & 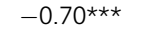 & - & - & - & - & - \\
\hline Recovery & $-0.25^{\star}$ & 0.20 N.S. & - & - & - & - \\
\hline Stick grab & 0.007 N.S. & 0.009 N.S. & 0.11 N.S. & - & - & - \\
\hline Lift from claws & $-0.28 * \star$ & 0.19 N.S. & 0.05 N.S. & $0.32^{\star *}$ & - & - \\
\hline Aggression & -0.03 N.S. & $0.26^{\star}$ & $0.33^{*}$ & 0.26 N.S. & $0.33^{* *}$ & - \\
\hline \multirow[t]{2}{*}{ Agitation } & -0.04 N.S. & 0.07 N.S. & -0.05 N.S. & 0.21 N.S. & 0.24 N.S. & $0.58^{\star \star \star}$ \\
\hline & \multicolumn{2}{|c|}{ TI attempts } & TI duration & \multicolumn{2}{|c|}{ Aggression } & Agitation \\
\hline \multicolumn{7}{|l|}{ (b) } \\
\hline TI duration & \multicolumn{2}{|c|}{$-0.78^{\star \star \star}$} & - & \multicolumn{2}{|c|}{ - } & - \\
\hline Aggression & \multicolumn{2}{|c|}{-0.24 N.S. } & -0.24 N.S. & \multicolumn{2}{|c|}{ - } & - \\
\hline Agitation & \multicolumn{2}{|c|}{0.14 N.S. } & -0.09 N.S. & \multicolumn{2}{|c|}{$0.64 * \star \star$} & - \\
\hline Breathing & \multicolumn{2}{|c|}{-0.14 N.S. } & 0.28 N.S. & \multicolumn{2}{|c|}{0.07 N.S. } & 0.002 N.S. \\
\hline
\end{tabular}

TI, tonic immobility; N.S., not significant. * $p<0.05 ; * * p<0.01 ; * * p<0.001$. Variables in italics (recovery in 2009 and breathing rate in 2010) were removed from final PCA analyses.

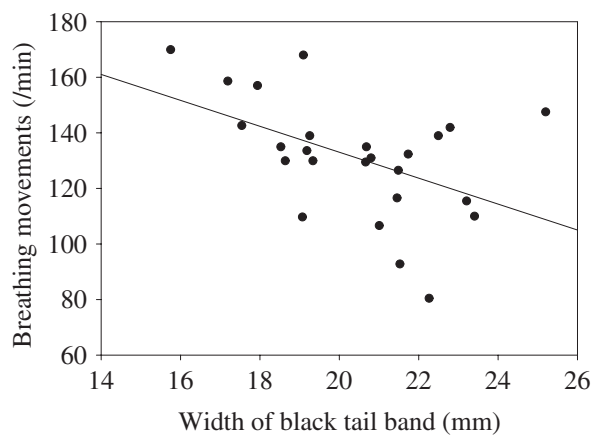

Fig. 3: Relationship between number of breathing movements and width of the sub-terminal black tail band in nestling kestrels in 2010.

agitated, grabbed a stick stronger and remained in TI longer. In 2010, we showed that individuals with a wider black tail band breathed slower. These results are very similar to those reported in barn owls (Van den Brink et al. 2012), with the exception of aggression (in kestrels, darker individuals were more aggressive while in the barn owls, lighter coloured individuals were more aggressive).

\section{Behaviour and Feather Melanin Content}

In contrast to eumelanin coloration, we did not detect any significant relationship between behaviour and the reddish brown pheomelanic coloration in both the kestrel and barn owl. The absence of covariation between these phenotypic traits is still unclear and might be specific to these two species or, alterna- tively, such covariations may occur under specific conditions. Indeed, other unpublished studies performed in the pheomelanic tawny owl (Strix aluco) showed that the degree of reddishness correlates with anti-predator behaviour (A. Da Silva, V. Van den Brink, G. Emaresi, E. Luzio, P. Bize \& A. Roulin, unpublished manuscript). On the basis of the chemical analyses of feather pigments, it could be that the traits we tested here are only influenced by variation in the amount of eumelanin and not of pheomelanin (in contrast, in the tawny owl, variation in the degree of reddishness is attributed to the variation in both eumelanin and pheomelanin feather content; Gasparini et al. 2009). Thus, more data need to be accumulated to investigate under which circumstances pheomelanism correlates with anti-predator behaviour. Note however, that in the barn owl, we found that only the degree of pheomelanin-based coloration is associated with dispersal distances (Van den Brink et al. 2012). Thus, it is possible that eumelanin and pheomelanin traits are correlated with different personality traits.

\section{Behavioural Syndromes}

The loadings onto the PCA show clear clusters of behavioural types. Even though the results from 2009 could not be replicated in 2010, the different types of behaviour cluster in the same manner both years (Fig. 3). The relatively low contribution to the total variance of $\mathrm{PC} 1$ and PC2 might be a further indication of this fact. The duration of TI, aggression and 
agitation all show a positive relationship to the sub-terminal black tail band in both years, whereas the number of attempts needed to induce TI is correlated negatively to it. It appears that these traits are different types of behaviour: confrontational (aggression, grabbing, agitation, refusal to remain in TI) vs. risk-avoiding (easy induction and long duration of TI). This apparent separation between the different types of behaviour suggests that they might be part of different behavioural axes as defined by Reale et al. (2007). It is tempting to place the two differently correlated behaviours on opposite ends of the boldness/ shyness axis. However, even though TI is commonly used to quantify fearfulness in poultry (Gallup 1977; Jones \& Faure 1981; Jones 1986), it can also have adaptive value, because it can increase survival after attack, presumably by causing the predator to loosen its grip (Thompson et al. 1981) or it might serve to divert the predator's attention away from the individual towards conspecifics (Erhard et al. 1999; Miyatake et al. 2009). Therefore, it is not certain whether TI is purely a 'fear' reaction, adding to the doubt whether fear is a behaviour that can adequately be measured (Boissy 1995; Erhard et al. 1999; Gregory 2008). This is why breathing rate was also measured, because we know this is related to stress (Carere \& Oers 2004).

\section{Differences Between Results Obtained in 2009 and 2010}

Our results point out that although we performed a number of similar tests in 2009 and 2010, the number and type of tests performed might cause variation in the results. We believe it is most likely the differences in results between the $2 \mathrm{yr}$ are not attributed to the difference in analysis method, because re-analysis of the 2009 data in the same way as in 2010 (i.e. with mean nest values) did not change our conclusions. We can however not completely exclude the possibility that the differences are caused by the different methods or reduced number of tests used. A last possibility is that the behaviour is influenced by environmental factors that change from year to year, which would not be surprising given that covariation between melanin-based coloration and other phenotypic attributes varies between environments as demonstrated by opposite relations between reproductive success and melanin-based coloration in tawny owls in two different populations (Brommer et al. 2005; Roulin et al. 2008), underlining that generalisations from field studies on animal personality are not easy to make as already mentioned by other authors (e.g. Bell 2005).
Similarity and Differences Between Kestrels and Other Species

We have several hypotheses to explain the inter-specific difference observed in the link between docility and coloration. Indeed, we found that kestrels displaying larger black tail bands were more aggressive towards human, whereas in barn owls, individuals showing larger black spots were less aggressive. From an ultimate point of view, it might pay off more to stay calm and quiet for the kind of predators a barn owl faces, whereas for a kestrel, the best might be to be more aggressive. The nocturnal barn owl and the diurnal kestrel might well face different predator pressures (diurnal predators are mainly avian, such as buzzards (Buteo buteo) and goshawks (Accipiter nisus), nocturnal predators are mainly mustelids or foxes (for recently fledged nestlings). The barn owl can in fact also be a threat to kestrels). There is some evidence that predation might select for boldness or docility (Reale \& Festa-Bianchet 2003). From a proximate point of view, this inter-specific difference in the sign of the association between boldness and melanin coloration could be explained by the level of stress. Indeed, the kestrel is diurnal and barn owl is nocturnal, implying that they may experience different levels of stress because of differences in human disturbance. The third option might be that differences are species specific, as demonstrated by the difference in breathing rate $(56.4 / \mathrm{min} \pm 1.2$ breathing movements for barn owls vs. $127 / \mathrm{min} \pm 2.8$ for kestrels) along with adult barn owls being calmer than adult kestrels when handled (pers. obs.). Finally, the differences between the species might be caused by different sex-linked associations between behaviour and coloration. In the barn owl, females display bigger black spots than males, whereas in kestrels, females display smaller black tail bands than males (Piault et al. in press). Thus, eumelanism is a typical femalelike trait in the barn owl and typical male-like trait in the kestrel. As a consequence, individuals behave as typical males when displaying small black spots in the barn owl and large black bands in the kestrel.

In both the kestrel and barn owl, eumelanin coloration is associated with behaviour and breathing rate. There are other examples of relationships between melanin colour and behaviour. A study on Marsh harriers (Circus aeruginosis), which display coloration most likely due to melanins, also showed different anti-predatory responses for males of different colour morphs (Sternalski \& Bretagnolle 2010). In this study, it was found that greyer males were far less often involved in mobbing a predator than browner males, 
while the number of alarm calls was similar between the two morphs, suggesting morph-specific roles. Boerner \& Kruger (2009) showed that in common buzzards (Buteo buteo), there were differences between different (supposedly eumelanic) morphs that were, interestingly enough, reversed between the two sexes. In males, lighter coloured individuals were more aggressive towards predators, whereas in females, it was the reverse. Towards conspecifics, both sexes responded most strongly to similarly coloured individuals. These two examples show that individual differences in behaviour related to melanin coloration can occur, although the relationships can be sex or species specific. Indeed, it has been found that within individuals, some phenotypic traits can be positively correlated with eumelanin content but negatively with pheomelanin content (Roulin et al. 2011). However, until the mechanism responsible for the covariance between behaviour and melanin colour traits has been clearly identified, as well as until the identity of melanin pigments have been determined in each species, it remains difficult to draw general conclusions.

\section{Acknowledgements}

The Swiss National Science Foundation supported the study financially (no. 3100A0_120517 to A.R.). We would like to thank Juan Carlos Senar and two anonymous reviewers for their useful comments on earlier versions of our manuscript.

\section{Literature Cited}

Almasi, B., Jenni, L., Jenni-Eiermann, S. \& Roulin, A. 2010: Regulation of stress response is heritable and functionally linked to melanin-based colouration.

J. Evol. Biol. 23, 987-996.

Becker, W. A. 1984: Manual of Quantitative Genetics, 4th edn. Academic Enterprises, Pullman, WA.

Bell, A. M. 2005: Behavioural differences between individuals and two populations of stickleback (Gasterosteus aculeatus). J. Evol. Biol. 18, 464-473.

Bennett, A. \& Hayssen, V. 2010: Measuring cortisol in hair and saliva from dogs: coat colour and pigment differences. Domest. Anim. Endocrinol. 39, 171-180.

Boerner, M. \& Kruger, O. 2009: Aggression and fitness differences between plumage morphs in the common buzzard (Buteo buteo). Behav. Ecol. 20, 180-185.

Boissy, A. 1995: Fear and fearfulness in animals. Q. Rev. Biol. 70, 165-191.

Brommer, J. E., Ahola, K. \& Karstinen, T. 2005: The colour of fitness: plumage colouration and lifetime reproduc- tive success in the tawny owl. Proc. Biol. Sci. 272, 935940 .

Carere, C. \& van Oers, K. 2004: Shy and bold great tits (Parus major): body temperature and breath rate in response to handling stress. Physiol. Behav. 82, 905912.

Dreiss, A. N. \& Roulin, A. 2010: Age-related change in melanin-based coloration of Barn owls (Tyto alba): females that become more female-like and males that become more male-like perform better. Biol. J. Linn. Soc. 101, 689-704.

Ducrest, A. L., Keller, L. \& Roulin, A. 2008: Pleiotropy in the melanocortin system, colouration and behavioral syndromes. Trends Ecol. Evol. 23, 502-510.

Erhard, H. W., Mendl, M. \& Christiansen, S. B. 1999: Individual differences in tonic immobility may reflect behavioural strategies. Appl. Anim. Behav. Sci. 64, 3146.

Fargallo, J. A., Laaksonen, T., Korpimäki, E. \& Wakamatsu, K. 2007: A melanin-based trait reflects environmental growth conditions of nestling male Eurasian Kestrels. Evol. Ecol. 21, 157-171.

Fucikova, E., Drent, P. J., Smits, N. \& van Oers, K. 2009: Handling stress as a measurement of personality in great tit nestlings (Parus major). Ethology 115, 366-374.

Gallup, G. G. 1974: Animal hypnosis - factual status of a fictional concept. Psychol. Bull. 81, 836-853.

Gallup, G. G. 1977: Tonic immobility - role of fear and predation. Psychol. Rec. 27, 41-61.

Gasparini, J., Bize, P., Piault, R., Wakamatsu, K., Blount, J. D., Ducrest, A. L. \& Roulin, A. 2009: Strength and cost of an induced immune response are associated with a heritable melanin-based colour trait in female tawny owls. J. Anim. Ecol. 78, 608-616.

Glutz von Blotzheim, U. N. 1987: Handbuch der Vögel Mitteleuropas. Aula-Verlag, Wiesbaden.

Gregory, P. T. 2008: Bluffing and waiting: handling effects and post-release immobility in a death-feigning snake (Natrix natrix). Ethology 114, 768-774.

Hayssen, V., Harper, J. M. \& DeFina, R. 2002: Fecal corticosteroids in agouti and non-agouti deer mice (Peromyscus maniculatus). Comp. Biochem. Physiol. A Mol. Integr. Physiol. 132, 439-446.

Ito, S., Nakanishi, Y., Valenzuela, R. K., Brilliant, M. H., Kolbe, L. \& Wakamatsu, K. 2011: Usefulness of alkaline hydrogen peroxide oxidation to analyze eumelanin and pheomelanin in various tissue samples: application to chemical analysis of human hair melanins. Pigment Cell Melanoma Res. 24, 605-613.

Jones, R. B. 1986: The tonic immobility reaction of the domestic fowl: a review. Worlds Poult. Sci. J. 41, 82-96.

Jones, R. B. \& Faure, J. M. 1981: Sex and strain comparisons of tonic immobility ("righting time") in the domestic fowl and the effects of various methods of induction. Behav. Process. 6, 47-55. 
Kittilsen, S., Schjolden, J., Beitnes-Johansen, I., Shaw, J. C., Pottinger, T. G., Sorensen, C., Braastad, B. O., Bakken, M. \& Overli, O. 2009: Melanin-based skin spots reflect stress responsiveness in salmonid fish. Horm. Behav. 56, $292-298$.

Lessels, C. M. \& Boag, P. T. 1987: Unrepeatable repeatabilities: a common mistake. Auk 104, 116-121.

Mafli, A., Wakamatsu, K. \& Roulin, A. 2011: Melaninbased colouration predicts aggressiveness and boldness in captive eastern Hermann's tortoises. Anim. Behav. 81, 859-863.

Mateos-Gonzàlez, F. \& Senar, J. C. 2012: Melanin-based trait predicts individual exploratory behaviour in siskins, Carduelis spinus. Anim. Behav. 83, 229-232.

Miyatake, T., Nakayama, S., Nishi, Y. \& Nakajima, S. 2009: Tonically immobilized selfish prey can survive by sacrificing others. Proc. Biol. Sci. 276, 2763-2767.

Piault, R., Van den Brink, V. \& Roulin, A. (in press): Condition-dependent expression of melanin-based colouration in the Eurasian kestrel. Naturwissenschaften, in press.

Quinn, G. \& Keough, M. 2002: Experimental Design and Data Analysis for Biologists. Cambridge Univ. Press, Cambridge.

Reale, D. \& Festa-Bianchet, M. 2003: Predator-induced natural selection on temperament in bighorn ewes. Anim. Behav. 65, 463-470.

Reale, D., Reader, S. M., Sol, D., McDougall, P. T. \& Dingemanse, N. J. 2007: Integrating animal temperament within ecology and evolution. Biol. Rev. 82, 291-318.

Rohwer, S. \& Wingfield, J. C. 1981: A field study of social dominance, plasma levels of luteinizing hormone and steroid hormones in wintering Harris sparrows. Z. Tierpsychol. 57, 173-183.

Roulin, A., Gasparini, J., Bize, P., Ritschard, M. \& Richner, H. 2008: Melanin-based colourations signal strategies to cope with poor and rich environments. Behav. Ecol. Sociobiol. 62, 507-519.

Roulin, A., Altwegg, R., Jensen, H., Steinsland, I. \& Schaub, M. 2010: Sex-dependent selection on an autosomal melanic female ornament promotes the evolution of sex ratio bias. Ecol. Lett. 13, 616-626.

Roulin, A., Almasi, B., Meichtry-Stier, K. S. \& Jenni, L. 2011: Eumelanin- and pheomelanin-based colour advertise resistance to oxidative stress in opposite ways. J. Evol. Biol. 24, 2241-2247.

Sternalski, A. \& Bretagnolle, V. 2010: Experimental evidence of specialised phenotypic roles in a mobbing raptor. Behav. Ecol. Sociobiol. 64, 1351-1361.

Thompson, R. K. R., Foltin, R. W., Boylan, R. J., Sweet, A., Graves, C. A. \& Lowitz, C. E. 1981: Tonic immobility in Japanese Quail can reduce the probability of sustained attack by cats. Anim. Learn. Behav. 9, $145-149$.

Van den Brink, V., Dolivo, V., Falourd, X., Dreiss, A. N. \& Roulin, A. 2012: Melanic colour-dependent antipredator behavior strategies in barn owl nestlings. Behav. Ecol. 23, 473-480.

Village, A. 1990: The Kestrel. T \& A. D. Poyser Ltd., London.

Wakamatsu, K., Ito, S. \& Rees, J. L. 2002: The usefulness of 4-amino-3-hydroxyphenylalanine as a specific marker of pheomelanin. Pigment Cell Res. 15, 225232. 